\title{
Pensamento algébrico nos anos iniciais do Ensino Fundamental: uma proposta de aplicativo
}

\author{
Vagner Campeão ${ }^{1}$ Túlio Oliveira de Carvalho(D)
}

\begin{abstract}
Resumo
Neste artigo, apresentamos um produto para o desenvolvimento do pensamento algébrico: o aplicativo Algebrizar. Sua construção baseou-se nas competências e habilidades requeridas pela Base Nacional Comum Curricular para os Anos Iniciais do Ensino Fundamental, aliadas à Estratégia de Investigação Matemática. As situações lúdicas são contempladas, pois o aplicativo possui o formato de um jogo, guiando o aluno através de trilhas e pontuações. O aplicativo procura incentivar a participação dos alunos nos momentos de reflexão, uma vez que, dentro do próprio jogo, ele precisa refletir e responder a algumas questões criadas com a intenção de promover um momento de diálogo e discussão em sala, situação que será conduzida pelo professor durante a investigação.
\end{abstract}

Palavras-chave: Pensamento Algébrico; Anos Iniciais do Ensino Fundamental; Investigação Matemática.

\begin{abstract}
We report on an applet for the development of algebraic thinking, named Algebrizar. Its construction was based on the competences and skills required by the official Base Nacional Comum Curricular for the early years of elementary school, combined with the strategy of Mathematical Investigation. The playful situations, which are also essential in the early years, are met through the use of the Algebrizar applet, which may be viewed as a game, guiding the student through trails and scores. Algebrizar is designed to encourage participation in moments of reflection, since within the game itself the student needs to reflect on and answer some questions created with the intention of promoting a moment of dialogue and discussion in the classroom, a situation that will be conducted by the teacher during the investigation.
\end{abstract}

Keywords: Algebraic Thinking; Early Years of Elementary School; Mathematical Investigation.

\section{Introdução}

Por meio da observação constante da natureza é que o homem construiu a Matemática ao longo dos séculos, analisando o seu cotidiano e considerando problemas afetos à sua sobrevivência. A partir da necessidade de soluções, foram sistematizados registros, análises e estudos que enfim levaram a uma linguagem com símbolos próprios.

\footnotetext{
${ }^{1}$ Bolsista da Coordenação de Aperfeiçoamento Pessoal de Nível Superior - Capes durante o curso de Mestrado em Matemática pelo Programa Profmat.
} 
A ação pedagógica no campo da matemática não tem sido satisfatória nos últimos anos, quando observamos os índices oficiais tais como o Índice de Desenvolvimento da Educação Básica (Ideb) apontando $71 \%$ de insuficiência na disciplina [1], posicionando-nos no $72^{\circ}$ posto de um total de 79 países no Programa Internacional de Avaliação de Estudantes (Pisa) [3]. A prática docente também permite a percepção da desmotivação e a desvalorização desta disciplina, tantas vezes sendo considerada muito difícil e para poucos. Isso se intensifica quando os temas da Álgebra são tratados, nos quais os alunos precisam lidar com o formalismo matemático e com símbolos.

Nesse estudo, partimos de uma análise da história do ensino da álgebra na Educação Básica. Por muito tempo, ela era inserida nos Anos Finais do Ensino Fundamental. Estudos recentes apontam que esse campo da matemática poderia ser tratado nos Anos Iniciais do Ensino Fundamental recorrendo ao desenvolvimento do pensamento algébrico para, posteriormente, estar preparado para a semeadura da linguagem algébrica.

Em [7, p.40], descrevendo o ensino da álgebra no decorrer do tempo, os autores relatam que este esteve associado à memorização de fórmulas, ou mesmo de regras mecânicas que solucionam expressões algébricas sem aplicabilidade e sentido. No ensino da matemática na Educação Básica, a álgebra foi inserida nos currículos de forma isolada e sem ligação com as demais áreas que já se estudavam: geometria e aritmética. O ensino era de caráter mecânico, reprodutivo e sem clareza. Os autores afirmam:

o modo como a maioria dos professores ainda trabalha a álgebra - de forma mecânica e automatizada, dissociada de qualquer significação social e lógica, enfatizando simplesmente a memorização e a manipulação de regras, macetes, símbolos e expressões - tal como ocorria há várias décadas, mostra que seu ensino não tem recebido a devida atenção. [7, p.40]

Mais recentemente, reporta-se em [4, p.4] a entrada conturbada da álgebra nos currículos escolares, no advento da Matemática Moderna, e que seu ensino desconexo tem causado repúdio nos alunos desde então. A resistência observada nos alunos quando o assunto é álgebra, principalmente por causa de sua linguagem, terá aqui uma proposta para ser contornada.

Este artigo propõe apresentar o aplicativo de nome Algebrizar, desenvolvido pelos autores, aliado à Investigação Matemática, a fim de encaminhar reflexões que promovem o desenvolvimento do pensamento algébrico nos anos iniciais do ensino fundamental alinhado à Base Nacional Comum Curricular (BNCC) por meio das suas habilidades e competências do campo da álgebra. Os objetivos deste artigo são os seguintes:

- compreender as demandas de aprendizagem dos anos iniciais do ensino fundamental, $1^{\circ}$ ao $5^{\circ}$ ano, pautadas nas competências e habilidades da BNCC;

- explorar estudos a respeito do pensamento algébrico como requisito para a linguagem algébrica;

- propor a Metodologia de Investigação Matemática aliada ao uso das tecnologias, como forma de alcançar o pensamento algébrico, já que este requer diálogo e trocas;

- propor as tarefas e modos de uso do aplicativo Algebrizar, criado com a intenção prioritária de desenvolver o pensamento algébrico por meio de discussões e levantamento de hipóteses. 


\section{Fundamentação Teórica e Aspectos Metodológicos}

Segundo [14, p.3], a álgebra é um conjunto de afirmações que caminham na produção de um significado em termos de números e operações aritméticas. É usada para expressar fatos genéricos, utilizando símbolos e códigos próprios manipuláveis, sendo essa uma de suas principais características. A leitura de uma expressão algébrica exige esforço para o entendimento do uso de símbolos, com vistas ao desenvolvimento do pensamento algébrico. O autor conclui que o que fortemente diferencia a álgebra da aritmética são os objetivos. O da aritmética está na resposta única e numérica e o da álgebra é uma resposta geral afirmável para vários valores numéricos.

Um traçado da história do ensino da álgebra, separado em três concepções, pode ser encontrado em [5, p.83]:

Linguístico-pragmática: desde o século XIX até metade do século XX, a álgebra foi apenas um instrumento de resolução de problemas. Eram procedimentos mecânicos representados pelos transformismos algébricos ${ }^{2}$ e isso era considerado suficiente para que o aluno adquirisse a capacidade de solucionar problemas matemáticos.

Fundamentalista-estrutural: a álgebra passa a ser a base de todos os outros campos da matemática. Tal concepção requereu que as estruturas e propriedades das operações, que justificam o transformismo algébrico, fossem ensinadas, acreditando que a partir daí o aluno teria aptidão para transpor esta habilidade a qualquer novo contexto que surgisse.

Fundamentalista-analógica: Há um retorno da álgebra como instrumento para a resolução de problemas, o que lhe atribui um valor prático, mas sem descartar a sua fundamentação, só que dessa vez recorrendo à geometria, ou seja, as justificativas das identidades algébricas pautaramse em demonstrações geométricas, acreditando-se que a "álgebra geométrica" era didaticamente superior à abordagem simbólica.

A intenção de modificar o atual cenário do ensino da álgebra nas escolas brasileiras mostra-se presente em estudos e em regulamentos recentes, nos quais foram aprovadas mudanças na organização dos currículos. Atualmente, o documento norteador no Brasil é a BNCC - Base Nacional Comum Curricular. Esse documento tem âmbito nacional e estabelece diretrizes para a educação nacional nas escolas públicas e privadas em caráter normativo.

Os anos iniciais do Ensino Fundamental, foco deste estudo, compreendem do $1^{\mathrm{o}}$ ao $5^{\mathrm{o}}$ ano, de 6 a 10 anos de idade. Nessa fase, segundo a BNCC, valorizam-se as situações lúdicas de aprendizagem com progressiva sistematização dessas experiências. Nessa etapa também se inicia a assimilação de novas formas de relação com o mundo, quando a criança experimenta o desenvolvimento das relações consigo mesma e com os outros.

A conexão entre a aquisição do conhecimento e o uso da fala, quando esta é oportunizada nas aulas, é defendida em [13]. A verbalização conecta a linguagem, o conhecimento, as experiências e as experiências de outros alunos com a matemática. "É preciso promover a comunicação pedindo aos alunos que esclareçam e justifiquem suas respostas, que reajam frente às ideias dos outros e que considerem pontos de vista alternativos."

A comunicação estabelece a troca de conhecimento entre alunos e entre alunos e professor. Cabe ao professor possibilitar situações para essas trocas, através de sua mediação, e isso só ocorre através

\footnotetext{
${ }^{2}$ Transformismo algébrico, segundo [5], refere-se à manipulação dos termos de uma expressão, com regras válidas, para a obtenção de outra expressão equivalente.
} 
de um planejamento de tarefas, configurando um ambiente em sala de aula que a favoreça, segundo $[8$, p.74].

Nesses estudos sobre o ensino de matemática [8, 13], a comunicação é vista como fator essencial para a apropriação dos conhecimentos matemáticos, através do ouvir o outro, do compartilhar experiências, inclusive do erro. A própria BNCC já prevê ambientes que favoreçam tais trocas nos anos iniciais do ensino básico, principalmente.

$\mathrm{O}$ advento da BNCC traz a álgebra como novidade para os professores dos anos iniciais. Anteriormente, ela era mencionada somente nos anos finais do Ensino Fundamental até o Ensino Médio. É válido destacar que a presença da álgebra já nos primeiros anos não pode e não deve requerer o formalismo ou as representações simbólicas, por mais simples que sejam. Essa unidade temática restringe-se a ideias de regularidades, generalizações de padrões e propriedades da igualdade, sendo, por exemplo, esta última definida da seguinte forma:

A relação de equivalência pode ter seu início com atividades simples, envolvendo a igualdade, como reconhecer que se $2+3=5$ e $5=4+1$, então $2+3=4+1$. Atividades como essa contribuem para a compreensão de que o sinal de igualdade não é apenas a indicação de uma operação a ser feita. [1, p. 270]

A álgebra é trazida como um elemento de um tipo de pensamento: o pensamento algébrico, que, segundo a BNCC, é "essencial para utilizar em modelos matemáticos na compreensão, representação e análise de relações quantitativas de grandezas e estruturas matemáticas". Dentre algumas habilidades, prevê que o aluno seja capaz de identificar regularidades, padrões em sequências numéricas e não numéricas, estabelecer leis que expressem relações entre grandezas, bem como criar, interpretar e transitar entre as diversas representações gráficas e simbólicas.

Em [5], após exporem vários exemplos de problemas, matemáticos e físicos, os autores defendem que o pensamento algébrico caracteriza-se pela "percepção de regularidades, percepção de aspectos invariantes em contraste com outros que variam, tentativas de expressar ou explicitar a estrutura de uma situação-problema e a presença do processo de generalização". Consequentemente, a construção do pensamento algébrico não seria realizada de modo isolado, mas na articulação entre os campos da matemática, e dessa com outras áreas de conhecimento.

Distinguindo a álgebra do pensamento algébrico, [8] caracteriza esse último como sendo as habilidades que possibilitam o uso de modelos algébricos, manipulação de expressões e aplicação de estruturas, chamando de pensamento analítico o que faz o aluno ser capaz de generalizar, abstrair relações e manipular a linguagem algébrica. Defende, portanto, que para constituir o pensamento algébrico é preciso tempo, o que pressupõe que isso deva ser induzido já no início da escolarização e gradativamente ganhar maior complexidade.

A necessidade do trabalho do desenvolvimento do pensamento algébrico logo nos primeiros anos de escolaridade é defendida em [4]. Estes autores trazem o ponto de vista de que o pensamento algébrico está relacionado à capacidade de aplicação de generalidade, variabilidade e estrutura. Em suma, o uso de símbolos, muito presente na álgebra, deve ser dominado pelo estudante, como também os significados, nos diversos contextos em que sejam aplicados, para que, enfim, esteja alcançado o pensamento algébrico.

Recorre-se, novamente, à BNCC para tornar clara uma competência geral do ensino fundamental, a Cultura Digital, que será subsídio para justificar a concepção do aplicativo: 
Compreender, utilizar e criar tecnologias digitais de informação e comunicação de forma crítica, significativa, reflexiva e ética nas diversas práticas sociais (incluindo as escolares) para se comunicar, acessar e disseminar informações, produzir conhecimentos, resolver problemas e exercer protagonismo e autoria na vida pessoal $e$ coletiva. [1, p. 9]

A BNCC cita que o advento da cultura digital trouxe mudanças na sociedade. Com o fácil acesso ao computador, telefone, celular e tablet, os jovens têm se tornado elemento principal nessa cultura, de modo que a interação social midiática os tem envolvido e de forma cada vez mais rápida [1, p. $61]$.

Na competência "Cultura Digital", o texto traz a diretriz de que, além de consumir essa tecnologia, é preciso tornar os alunos competentes em produzi-la, ao passo que também prevê que o aluno a compreenda de forma crítica, significativa, reflexiva e ética. Em outras palavras, as tecnologias na educação devem ir além do seu uso, chegando à produção e à compreensão.

Partindo dessa premissa, a escola atualiza-se em um novo papel.

\begin{abstract}
É importante que a instituição escolar preserve seu compromisso de estimular a reflexão e a análise aprofundada e contribua para o desenvolvimento, no estudante, de uma atitude crítica em relação ao conteúdo e à multiplicidade de ofertas midiáticas e digitais. [1, p. 61]
\end{abstract}

Por outro lado, o mundo digital tem conduzido a sociedade ao imediatismo de respostas e a um quadro de informações passageiras, o que leva a análises superficiais, segundo a BNCC. Portanto, a escola deve ressignificar os modos de comunicação e as linguagens para que, então, "eduque para usos mais democráticos das tecnologias e para a participação consciente na cultura digital". É dessa forma de significar a presença e o uso das tecnologias na educação que a escola pode, conforme a BNCC [1, p. 61], "promover situações de aprendizagem, a interação e o compartilhamento de significados entre professores e estudantes".

Considerando o propósito de criar e manter um ambiente de trocas, diálogos para o desenvolvimento do pensamento e da linguagem, a Metodologia de Investigação Matemática coloca-se como uma escolha natural: "Afinal, quem investiga está a procurar aprender, e quem aprende pode ter muito interesse em investigar" [10, p. 1]. O autor diz que não deveríamos separar o aprender do investigar. Ele ainda pontua que o "investigar" não é mais do que procurar conhecer e encontrar soluções para os problemas que surgem, elevando a investigação a uma capacidade de primeira importância para os cidadãos que, portanto, deve estar presente na escola. Na definição do "aprender", especificamente em matemática, seu estudo diz que é

O desenvolvimento integrado e harmonioso de um conjunto de competências e capacidades, que envolvem conhecimento de factos específicos, domínio de processos, mas também capacidade de raciocínio e de usar esses conhecimentos e processos em situações concretas, resolvendo problemas, empregando ideias e conceitos matemáticos para lidar com situações das mais diversas, de modo crítico e reflexivo. [10, p.3]

Aqui vale especificar como é uma atividade de investigação matemática. Em [11, p.20], os autores descrevem momentos dentro desse tipo de atividade, que constam no Quadro 1. 


\begin{tabular}{|c|l|}
\hline Exploração e formulação de questões & $\begin{array}{l}\text { Reconhecer uma situação problema, explorar a situação } \\
\text { problema e formular questões }\end{array}$ \\
\hline Conjecturas & Organizar dados e formular conjecturas \\
\hline Testes e reformulação & Realizar testes e refinar uma conjectura \\
\hline Justificação e avaliação & $\begin{array}{l}\text { Justificar uma conjectura e avaliar o argumento e sua } \\
\text { conclusão }\end{array}$ \\
\hline
\end{tabular}

Quadro 1: Momentos na realização de uma atividade. Fonte: [11, p.20]

O ato de investigar em matemática deve considerar que uma atividade deva englobar a identificação de questões, a formulação, o teste e a prova de conjecturas, a argumentação, a reflexão e a avaliação do próprio trabalho [12, p.20]. Esse tipo de abordagem ainda é pouco encontrado nos livros didáticos, como atestam os estudos [6, 9], por exemplo.

Em resumo, o contexto histórico do ensino da matemática coloca a álgebra no ensino regular como fonte de preocupação, visto que a sua abordagem tardia pode causar falhas na aprendizagem desse campo da matemática. Para que o ensino da álgebra possa acontecer desde os anos iniciais do ensino fundamental, deve-se lembrar que se evite o formalismo simbólico das representações algébricas. O desenvolvimento do pensamento algébrico requer, antes, o diálogo e a interação, além da criação de um ambiente pedagógico propício para a discussão de conjecturas, testes e levantamento de hipóteses, momentos tais que o símbolo, a ideia de generalidade e regularidade poderão dar espaço para uma cognição que torne o aluno preparado para a álgebra, tal como ela deve acontecer nos anos finais do Ensino Fundamental e Ensino Médio.

A Cultura Digital é hoje vista como uma das competências gerais da Educação Básica, marcada pela presença da tecnologia e as mudanças causadas por esta na comunicação, bem como na sociedade. Este trabalho vai ao encontro de tal diretriz ao propor situações matemáticas aliadas ao uso das tecnologias. No que tange ao ambiente de trocas e franca comunicação, conduzido pelo professor, lembramos que os estudos analisados $[8,13]$ reforçam que a comunicação na aprendizagem de matemática é essencial, justificando o uso da estratégia de investigação matemática, aliada à tecnologia. Entendemos que as atividades de investigação matemática promovem oportunidades de explorar conceitos matemáticos importantes, desenvolvem a capacidade de encaminhar processos matemáticos e possibilitam a inclusão de alunos com diferentes graus de aprendizagem, respeitando seus ritmos.

\section{O aplicativo Algebrizar}

Para o cumprimento da proposta deste artigo, um aplicativo foi criado pelos autores na intenção de mediar o trabalho do professor nos momentos de investigação. Tal estratégia pressupõe o diálogo e a participação sistemática dos alunos, que devem propor soluções, conjecturar e questionar. Frente ao desafio dos educadores de promover a participação de todos os estudantes, o aplicativo tem também o papel de incentivador promovendo, ao mesmo tempo, o uso da tecnologia nas práticas pedagógicas objetivando o protagonismo e a autonomia dos alunos na própria aprendizagem.

O aplicativo de nome Algebrizar é uma coletânea de problemas fundamentada nas habilidades e competências da BNCC em formato de jogo, guiando o aluno na aquisição de conceitos e reflexões sobre regularidade, variação e generalização, principalmente no estudo de sequências, padrões e igualdades. Na sua função enquanto jogo, o Algebrizar tem a proposta de monitorar o desempenho dos alunos no entendimento dos conceitos, que podem ou não ser previamente trabalhados pelos professores. Como uma ferramenta pedagógica, sua proposta visa estimular o pensamento algébrico 
que, antecedendo a linguagem algébrica, requer diálogo, discussão, levantamento de hipóteses e conclusões individuais ou coletivas.

Relata-se a seguir como foi a produção e concepção do aplicativo para uma melhor compreensão da sua relação com o pensamento algébrico e dos benefícios do seu uso quando aliado à investigação matemática. A programação necessária para a sua produção foi executada exclusivamente pelo primeiro autor.

Uma vez que o foco da proposta são os alunos dos anos iniciais do Ensino Fundamental, o aplicativo precisava ter uma característica lúdica (cores, imagens e sons), fragmentada e progressiva (fases, pontuações e telas), o que exigia um produto que estivesse em constante interação com o aluno durante o seu uso. Para atingir essa demanda o aplicativo faz uso de três plataformas: Kodular, phpMyAdmin e páginas PHP.

O Kodular é um ambiente de desenvolvimento de aplicativos para celulares Android em forma de blocos encaixáveis e programáveis. Sua plataforma é aberta e de uso livre, tem a intenção de disseminar a criação de programas para leigos ou de conhecimentos avançados.

O phpMyAdmin é um banco de dados, local onde ficarão as informações sobre pontuação, nível de desempenho dos alunos, cadastros de usuários e as observações feitas pelos alunos durante o uso do Algebrizar. O que motiva a escolha dessa plataforma é que as informações não ficarão armazenadas no celular do usuário, portanto podem ser alteradas com o tempo. Por exemplo, as perguntas motivadoras que garantirão o momento de investigação podem ser modificadas quando se tornarem obsoletas, sem que haja a necessidade de instalar novamente o aplicativo ou fazer uma atualização.

As páginas $P H P$ constituem uma linguagem de programação voltada para o desenvolvimento de páginas web. No aplicativo, seu uso é intercalado com o processamento do celular. Informações como pontuação, questionamentos, observações e desempenho que estarão fora do celular do usuário são processadas nestas páginas.

Outra ferramenta usada na produção do jogo é o de reconhecimento de fala e conversão em texto (e de texto em voz) nativo nos celulares, uma ferramenta da empresa Google. Na intenção de preservar a característica de fala, simulando um ambiente de conversa, o jogo anuncia as fases pelas quais o aluno vai passar, dá explicação às regras da atividade e felicita as conquistas. Por outro lado, quando é exigido do aluno uma resposta ou um comentário, esse momento também é de conversa, ou seja, o aluno fala e, através dessa ferramenta, o áudio é convertido em texto.

Com esse conjunto de plataformas e ferramentas de produção, o aplicativo Algebrizar pode ser instalado em um celular ou tablet cujo sistema operacional seja Android. Seu uso requer uma conexão com a internet.

A ferramenta encontra-se disponível na loja de aplicativos do Google para download. Utilizando o aplicativo Play Store ${ }^{3}$, deve-se procurar pelo jogo Algebrizar. Sua licença de uso é gratuita.

A usabilidade do Algebrizar segue por meio de cadastros simples. O professor é o usuário que guiará o fluxo do jogo. Inicialmente, o professor precisa fazer o seu cadastro. A tela é mostrada na Figura 1.

\footnotetext{
${ }^{3}$ Aplicativo de propriedade da empresa Google responsável pelo repositório de jogos e aplicativos do sistema Android, local onde está disponível o jogo Algebrizar.
} 
Somente algumas informações

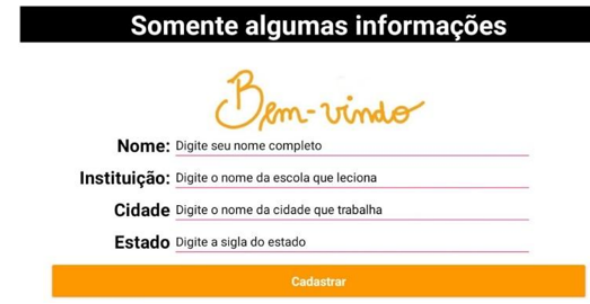

Figura 1: Tela de cadastro de professor. (Fonte: do autor)

Trata-se de uma coleta simples de informações. O jogo não exige e-mail nem confirmação do usuário, pois considera-se não haver a necessidade de segurança de dados, e que a finalidade do aplicativo é educacional, não fazendo uso de informações sigilosas nem pessoais. Ao final de um cadastro os futuros acessos dos professores serão realizados através de códigos numéricos, e esses serão informados no ato do cadastro.

Em seguida, os professores precisam cadastrar suas salas e vincular os seus alunos a elas. A tela é mostrada na Figura 2. Esta ação gerará os códigos numéricos dos alunos, que passarão a ser usuários do aplicativo (deverão ser informados os nomes dos alunos e as salas em que estudam).

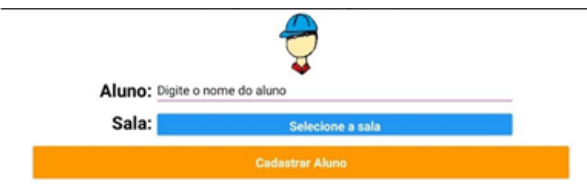

Figura 2: Tela de cadastro de alunos. (Fonte: do autor)

Os professores deverão divulgar aos alunos os códigos de acesso para o início do jogo, que estarão em sua posse após os cadastros. Os filtros de acessos através de códigos de usuários tornam-se necessários para que o professor faça o acompanhamento do desempenho dos alunos nas atividades propostas, bem como observar os comentários deixados por eles nos momentos de reflexão, fazendo a identificação dos alunos e suas ações, situação que não é possível em aplicativos de jogos usuais, sem cadastros prévios.

É função do professor liberar as habilidades que ele deseja permitir que os alunos joguem. Neste caso, ele pode permitir ou bloquear fases do jogo conforme seu objetivo e usar tal ferramenta durante o ano nos momentos em que desejar propor o trabalho com a álgebra, sem que as propostas do jogo esgotem-se logo de início.

Para o professor, as opções disponíveis estão representadas na Figura 3: 


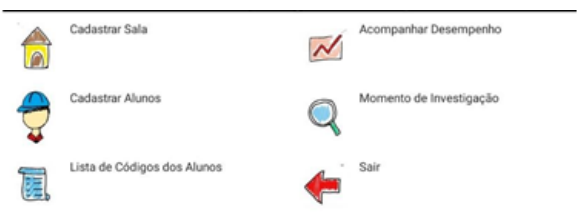

Figura 3: Tela de opções dos professores. (Fonte: dos autores)

Os alunos ingressarão no jogo através do código de acesso fornecido pelo seu professor e, diante das habilidades liberadas pelo mesmo, iniciarão as atividades. A Figura 4 a seguir descreve as opções disponíveis para os alunos:

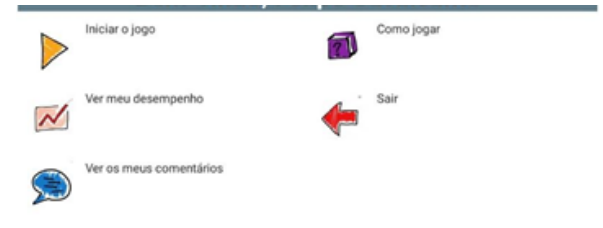

Sala: Professor: Vagner

Figura 4: Tela de opções de alunos (Fonte: do autor)

O Algebrizar segue um roteiro dividido em fases, denominadas jornadas e trilhas. A proposta do jogo está diretamente ligada às habilidades de Matemática da unidade temática Álgebra descritas na BNCC. Cada jornada representa uma habilidade e as trilhas representam o caminho que o aluno seguirá no jogo para finalizar esta jornada; em outras palavras, para alcançar a habilidade.

Cada trilha consiste de uma série de problemas que explorarão os conceitos por trás das habilidades. Os alunos só avançam para a trilha seguinte ao alcançar 250 pontos. Ao final de cada trilha o aluno é levado para uma seção de investigação, momento em que se depara com uma pergunta que pretende induzi-lo a fazer conclusões, observações, análises e conjecturas, não havendo respostas certas ou erradas. Por fim, quando todas as trilhas forem concluídas a jornada é dada como finalizada.

Baseado no planejamento do professor e na realidade local, o jogo pode ser usado dentro da sala de aula como também em casa, adequando-se ao seu objetivo. Entretanto, o uso do Algebrizar nas aulas não pode estar limitado à realização dessas atividades na tela de um celular. Nesse sentido trata-se apenas de uma coletânea de problemas, o que não basta para alcançar o pensamento algébrico.

Na organização de uma proposta de investigação matemática, conforme [11], o aplicativo encaminhará parte desse processo, promovendo momentos de exploração, contato com diversas situações e problemas para resolver, seguido de um momento para refletir, organizar e fazer conjecturas. No caso específico da álgebra, esses momentos levam o aluno a reconhecer padrões e analisar variações de quantidades, com a meta de descrever tais situações com generalidade. 
De posse desses levantamentos, o professor deve analisar as respostas com a intenção de agrupar os diferentes níveis de alcance da habilidade e criar um ambiente de diálogo e discussão com essas observações realizadas durante o jogo, validando-as ou não, por meio de testes. Nesse ambiente, refinar um argumento válido, justificar os posicionamentos e avaliar as conjecturas que os alunos formularam torna-se possível. Considerando que todos os alunos que participam do jogo tiveram acesso às mesmas questões durante as trilhas, destaca-se o papel de mediador do professor, ao acolher as diversas interpretações e formulações surgidas. O Quadro 2 descreve a síntese do processo de investigação proposto:

\begin{tabular}{|c|l|}
\hline Exploração e formulação de questões & $\begin{array}{l}\text { Realização das tarefas, baseadas nas habilidades da } \\
\text { BNCC, através do jogo Algebrizar, conquistando pon- } \\
\text { tos e vencendo as trilhas. }\end{array}$ \\
\hline Conjecturas & $\begin{array}{l}\text { Momento de reflexão no Algebrizar com uma pergunta } \\
\text { motivadora em que o aluno é levado a concluir regras ou } \\
\text { levantar hipóteses sobre determinada situação tratadas } \\
\text { no momento de exploração. }\end{array}$ \\
\hline Testes e reformulação & $\begin{array}{l}\text { A partir das respostas, o professor precisa agrupar e } \\
\text { analisar os níveis de comentários e promover um mo- } \\
\text { mento de diálogo e trocas na sala, encaminhando a } \\
\text { turma para uma conclusão colaborativa, promovendo } \\
\\
\text { o pensamento algébrico. }\end{array}$ \\
\hline Justificação e avaliação & $\begin{array}{c}\text { Analisar as conclusões a que chegarem, fazendo uma } \\
\text { avaliação do processo e das conclusões. }\end{array}$ \\
\hline
\end{tabular}

Quadro 2: Ações da Investigação Matemática com o uso do aplicativo Algebrizar e mediação do professor.

Para exemplificar as trilhas e jornadas do aplicativo, será abordada a jornada número um do quarto ano do Ensino Fundamental, intitulada "A ordem dos múltiplos". Essa jornada possui três trilhas que levarão o aluno a alcançar a habilidade que está ilustrada na Figura 5:

EF04MA11 - Identificar regularidades em sequências numéricas compostas por múltiplos de um número natural.

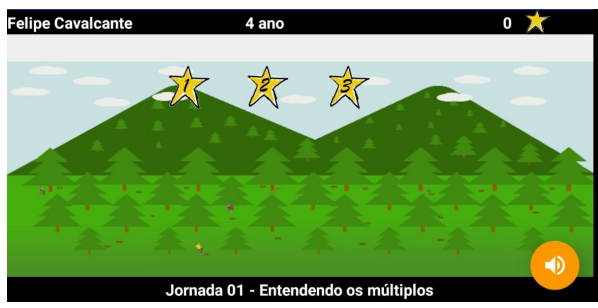

Figura 5: Tela inicial da jornada "Entendendo os Múltiplos". (Fonte: do autor)

A primeira trilha é chamada "Observe as mudanças" e tem o objetivo de fazer o estudante observar 
o comportamento de uma sequência quando se altera o padrão que a forma. Ela é caracterizada por uma situação onde o aluno escolhe um número natural qualquer e digita-o para formar sequências. Ao gerá-la, os primeiros dez múltiplos desse número (incluindo o zero) se apresentarão em uma sequência crescente, podendo ainda ser estendida com os dez múltiplos seguintes, pressionando o botão disponível. É interessante mencionar a facilidade que o aplicativo terá em fornecer as sequências, mesmo para números com dois ou mais algarismos, o que contempla uma grande diversidade de exemplos para a sala de aula. A cada formação de sequência distinta, o aluno aumenta seus pontos para concluir essa trilha. Finalizados os 250 pontos dessa trilha o aluno será parabenizado e encaminhado para a tela de reflexão que possui algumas perguntas, como as ilustradas na Figura 6:

- Existe algum número que esteja em todas as sequências?

- Cada número gera uma sequência totalmente diferente?

- Será que existe alguma sequência composta por todos os números?

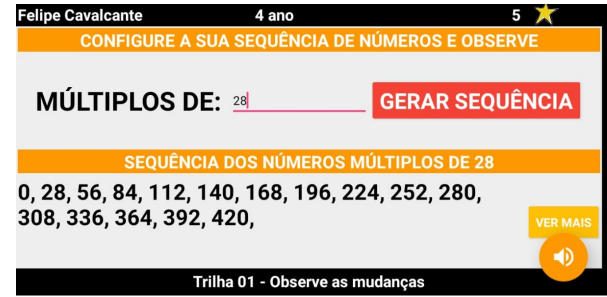

Figura 6: Tela da trilha um: Observe as mudanças. (Fonte: do autor)

A trilha dois, "Completando sequências", possui o objetivo de completar sequências através da regra de formação dada. De forma inversa à trilha um, nessa etapa o aluno precisa descobrir e seguir a regra de formação da sequência, apontando quais termos faltam. Os números que geram as sequências são aleatórios (entre 1 e 100) e podem iniciar por qualquer termo (não necessariamente do zero). As três primeiras sequências dadas terão o seu padrão de formação identificado (por exemplo, múltiplos de 2, múltiplos de 7), enquanto as demais exigirão estratégias dos alunos para identificar e completar. Em todas as sequências o aluno terá três lacunas para preencher, conforme mostra a Figura 7, e ir pontuando até 250, momento em que será levado para as seguintes reflexões:

- Como você faz para encontrar um número em uma sequência de múltiplos?

- Você é capaz de descobrir qualquer um deles? 


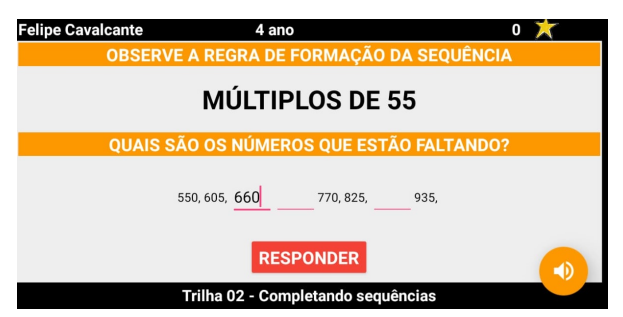

Figura 7: Tela da trilha dois: Completando sequências. (Fonte: do autor)

Para encerrar essa jornada, a trilha três, "Observe com atenção", cujo objetivo é adquirir uma noção mais consolidada do padrão progressões aritméticas, leva o aluno a refletir sobre as características dos números que as compõem, observando os múltiplos, como indicado na Figura 8. Espera-se que identifique que os números múltiplos de dois são todos pares, que os múltiplos de dez são terminados em zero e que os múltiplos de seis constam nas tabuadas do número dois e três. A cada noção adquirida de características comuns a pontuação vai aumentando até a pontuação máxima e, por fim, para as questões

- Que características os múltiplos de 5 têm em comum?

- E os múltiplos de 4 ?

- E os de 11? (escreva no seu caderno suas observações)

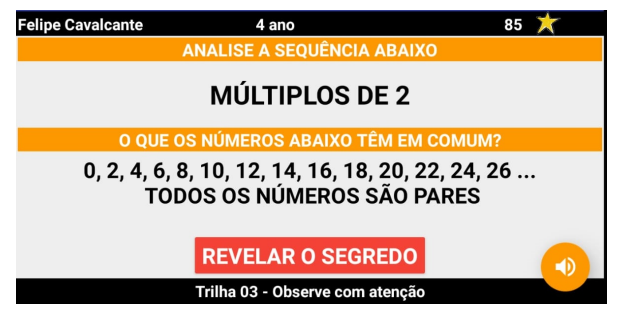

Figura 8: Tela da trilha três: Observe com atenção. (Fonte: do autor)

Após as três trilhas, a jornada é finalizada e então o momento de investigação deve ser conduzido em sala de aula, lembrando que o professor terá acesso às observações feitas pelos seus alunos. É importante que cada trilha tenha um momento de discussão e trocas em sala e que o professor separe os levantamentos feitos por nível de entendimento.

As perguntas de cada trilha têm a intenção de conduzir o aluno a ser capaz de fazer generalizações; nesse caso, a respeito de sequências em progressão aritmética.

Por fim, cabe mencionar a possibilidade, dentro do aplicativo, para os professores enviarem feedbacks das questões de investigação. Nessa tela os professores podem enviar sugestões de novas questões ou reformulações. Trata-se de um movimento colaborativo, o que faz o aplicativo estar 
em permanente construção, trazendo ainda a possibilidade de evoluir sua aplicabilidade em sala com o uso dos professores a quem o aplicativo se destina.

\section{Considerações Finais}

A Matemática, por possuir sua própria simbologia e representações, exige muitas vezes um elevado grau de abstração. Careceria sentido iniciar a linguagem algébrica no Ensino Fundamental, por volta do $7^{\circ}$ e $8^{\circ}$ anos, sem que o aluno tenha os princípios do pensamento que lhe poderão garantir o domínio dessa linguagem.

É acreditando na importância de iniciar a Álgebra nos primeiros anos de aprendizagem, a fim de minimizar as grandes dificuldades encontradas pelos professores e alunos quando iniciam assuntos como equações ou produtos notáveis, que se apresenta uma proposta de prática docente que promova o desenvolvimento do pensamento algébrico. Generalizar, identificar padrões, usar símbolos e perceber variação não são alcançados somente por meio dos problemas neste estudo; momentos de diálogo que promovam trocas de ideias são requisitos para a exploração da álgebra, principalmente nessa etapa de ensino em que a criança experimenta o desenvolvimento das relações consigo e com os outros, o que torna a Investigação Matemática ideal para esse objetivo.

Com o jogo, pretendeu-se valorizar situações lúdicas de forma a incentivar a participação dos alunos diante de questionamentos que poderão servir de subsídio para a Investigação Matemática, que traz em seu bojo o questionamento, o levantamento e a formulação de hipóteses e, mediados pelos professores, a conclusão.

Durante a produção do aplicativo foram formulados problemas ligados às habilidades contidas na BNCC, que são priorizadas pelas trilhas em um caminho pelo qual o aluno pode explorar e percorrer para dominar tal habilidade, seguido de um momento de reflexão e elaboração de conjecturas. Justamente por isso, sugere-se aos professores que priorizem os momentos de testes e avaliação, analisando detidamente as observações deixadas pelos alunos durante o jogo, pois elas deverão ser as norteadoras da investigação em sala.

\section{Referências}

[1] BRASIL. Ministério da Educação. Base nacional comum curricular. Brasília: MEC/SEB, 2017. Disponível em: <http://basenacionalcomum.mec.gov.br>. Acesso em: 10 de março de 2020 .

[2] BRASIL. Ministério da Educação - Inep. Resumo técnico. Resultados do índice do desenvolvimento da Educação Básica. Brasília: INEP / Ministério da Educação, 2017.

[3] BRASIL. Ministério da Educação - Inep. Relatório Brasil no Pisa 2018 - Versão preliminar. Brasília: Inep / Ministério da Educação, 2018.

[4] BORRAlHO, A; BARBOSA, E. Pensamento algébrico e exploração de padrões.. APM Associação dos Professores de Matemática, 2009. Disponível em: <http://www.apm.pt/files/ Cd_Borralho_Barbosa_4a5752d698ac2.pdf>. Acesso em: 28 de novembro de 2016.

[5] FIORENTINI, D; MIORIM, M A; MIGUEL, A. Contribuição para um repensar ... a Educação Algébrica Elementar. Pro-Posições. Campinas, 1993.

[6] LOPES, A. Análise de uma coleção de livros didáticos para o ensino médio. Dissertação de Mestrado. Profmat (2013) 
[7] Miguel, A; FIOREnTINI, D; MiORIM, M. A. Álgebra ou Geometria: para onde Pende o Pêndulo?. Pro-Posições. Campinas, 1992.

[8] NACARATO, A M.; CUSTÓDIO, I A. O desenvolvimento do pensamento algébrico na Educação Básica: compartilhando propostas de sala de aula com o professor que ensina (ensinará) matemática. Brasília. Sociedade Brasileira de Educação Matemática. 2018.

[9] PASSOS, D. S.; MARIANI, R. C. P. Uma análise do livro didático "Tudo é Matemática" a partir dos registros mobilizados na educação algébrica no $8^{\circ}$ ano do Ensino Fundamental. Caminhos da Educação Matemática em Revista (online). v. 2, pp. 72-82, 2014.

[10] PONTE, J. P. Investigar, ensinar e aprender In: Actas do ProfMat 2003. (CDROM, pp.2539). Lisboa: APM, 2003.

[11] PONTE, J. P.; BROCARDO, J.; OLIVEIRA, H. Investigações Matemáticas na Sala de Aula 2. ed. Belo Horizonte: Autêntica, 2009.

[12] PONTE, J. P.; OLIVEIRA, H.; CUNHA, H. Investigações Matemáticas na Sala de Aula In: Actas do Profmat 1995 (p. 161 a 167), Lisboa: APM, 1995

[13] SMOLE, K S; DINIZ, M I. Comunicação em matemática: instrumento de ensino e aprendizagem.. Disponível em: <https://mathema.com.br/artigos/ comunicacao-em-matematica-instrumento-de-ensino-e-aprendizagem/>. Acesso em: 31 de março de 2020.

[14] TELES, R A M. A aritmética e álgebra na matemática escolar. Anais do VIII Enem - Encontro Nacional de Educação Matemática - Minicurso GT 2 - Educação Matemática nas Séries Finais do Ensino Fundamental - 2004.

Vagner Campeão

Universidade Estadual de Londrina <vcampeao@hotmail.com>

Túlio Oliveira de Carvalho

Universidade Estadual de Londrina <tuliocarvalho@uel.br>

Recebido: 11/09/2021

Publicado: 25/05/2021 